原著

\title{
海綿静脈洞部動脈瘤の直達手術
}

\author{
沼 沢 真一，鈴木 恭一，浅 利 潤
}

渡辺 善一郎, 佐々木 達也, 児玉 南海雄

\section{Direct Surgical Approach to Cavernous Portion Aneurysm}

Shinichi Numazawa, M.D., Kyoichi Suzuki, M.D., Jun Asari, M.D.,

Zenichiro Watanabe, M.D., Tatsuya Sasaki, M.D.,

and Namio Kodama, M.D.

Department of Neurosurgery, Fukushima Medical School, Fukushima, Japan

Summary : Nine cases of cavernous portion aneurysm (AN) were treated by direct surgery.

One $\mathrm{AN}$ was a persistent trigeminal artery $\mathrm{AN}$ at the $\mathrm{C}_{4-5}$ portion, five $\mathrm{ANs}$ were located at the $\mathrm{C}_{3}$ portion and the other three were ophthalmic $\mathrm{ANs}$ of the subchiasmal type at the $\mathrm{C}_{2}$ portion.

In four cases, subarachnoid hemorrhage occurred as a result of a saccular aneurysm located at the $\mathrm{C}_{2}$ portion (three cases) and at Acom accompanied by a $\mathrm{C}_{3}$ portion $\mathrm{AN}$ (one case). In two cases, epistaxis occurred as a result of a saccular aneurysm located at the $\mathrm{C}_{3}$ portion. In one case, ophthalmoplegia occurred suddenly. And in two other cases, aneurysms were incidentaliy discovered by angiography.

Operation was performed under normotensive, normothermic anesthesia in a half sitting position with the head lifted up by approximately $35^{\circ}$. In this position, it was easy to control venous bleeding from the cavernous sinus owing to reduction of venous pressure. Intraoperative monitoring was performed to evaluate cerebral blood flow (CBF), somatosensory evoked potential (SEP) and visual evoked potential (VEP).

The subtemportal approach was used for a $\mathrm{C}_{4-5} \mathrm{AN}$ and the pterional approach was used for $\mathrm{C}_{2-3}$ ANs with the removal of the anterior clinoid process. Bleeding from the opened cavernous sinus was controlled with Oxycel packing. Doppler sonography was useful for checking on the patency of the internal carotid artery.

All nine aneurysms were clipped with no stenosis of the carotid artery. There was no major ischemic complication, but ipsilateral blindness (2 cases), ophthalmoplegia (1 case), transient oculomotor palsy ( 1 case) and transient CSF rhinorrhea (1 case) were observed.

Details of direct surgery on the nine cases of cavernous portion aneurysms are reported in this paper.

\section{はじめに}

海綿静脈洞部の直達手術は従来非常に困難であると考え られてきたが，最近ではかなり多くの直達手術の報告がみ られるようになってきている。我々はこれまで 9 例の海綿 静脈洞部動脈瘤の直達手術例を経験したので，手術手技を
Key words :

- cavernous sinus

- direct surgical approach

- aneurysm

福島県立医科大学 脳神経外科 
Table 1 Summary of cases

\begin{tabular}{|c|c|c|c|c|}
\hline \multirow{2}{*}{$\begin{array}{l}\text { Case } \\
\text { No. }\end{array}$} & \multirow{2}{*}{$\begin{array}{l}\text { Age } \\
\text { Sex }\end{array}$} & \multirow{2}{*}{$\begin{array}{l}\text { Site of } \\
\text { aneurysm }\end{array}$} & \multicolumn{2}{|c|}{ Signs \& symptoms } \\
\hline & & & preoperative & postoperative \\
\hline 1 & $53 \mathrm{~F}$ & $\begin{array}{l}\text { rt. IC-PTA }\left(\mathrm{C}_{4-5}\right) \\
\& \text { IC-PC }\end{array}$ & $\begin{array}{l}\text { ophthalmoplegia } \\
\text { ocular pain }\end{array}$ & ophthalmoplegia \\
\hline 2 & $52 \mathrm{~F}$ & rt. IC $\left(\mathrm{C}_{3}\right)$ & epistaxis & diplopia* \\
\hline 3 & $58 \mathrm{M}$ & lt. IC $\left(\mathrm{C}_{3}\right)$ & epistaxis & none \\
\hline 4 & $50 \mathrm{~F}$ & rt. IC $\left(\mathrm{C}_{3}\right)$ & SAH & none \\
\hline 5 & $61 \mathrm{M}$ & rt. IC $\left(\mathrm{C}_{3}\right)$ & incidental & rt. blindness \\
\hline 6 & $50 \mathrm{~F}$ & lt. IC $\left(\mathrm{C}_{3}\right)$ & incidental & none \\
\hline 7 & $66 \mathrm{~F}$ & lt. ophthalmic & SAH & rhinorrhea* \\
\hline 8 & $60 \mathrm{~F}$ & lt. ophthalmic & $\mathrm{SAH}$ & lt. blindness \\
\hline 9 & $56 \mathrm{~F}$ & lt. ophthalmic & SAH & none \\
\hline
\end{tabular}

* transient

脈・遺残三叉動脈分岐部動脈瘤 $\left(\mathrm{C}_{4-5}\right)$ が 1 例, $\mathrm{C}_{3}$ の海綿 静脈洞内動脈瘤が 5 例， $\mathrm{C}_{2}$ の内頸動脈・眼動脈分岐部動 脈瘤 (subchiasmal type) が 3 例である。発症時の症状は, クモ膜下出血が 4 例, 大量の鼻出血が 2 例, 突然の脳神経 麻瘏が 1 例, 脳梗塞抢よび神経膠腫に合併した incidental なものが 2 例であった (Table 1). クモ膜下出血をきたし た 4 例中 3 例は $\mathrm{C}_{2}$ の動脈瘤で, もう 1 例は合併していた 前交通動脈瘤の破裂によるクモ膜下出血と考えられた。

\section{手術手技}

\section{1. 手術における留意点}

麻酔は常温・常圧で, 体位は頭蓋内静脈圧を下げ海綿静 脈洞からの出血に備える目的で, 頭部を約 $35^{\circ}$ 挙上した half sitting position とする.この程度の頭部挙上であれば air embolism が問題となることはまずない.

通常頸部内頸動脈は確保するが, 最近では balloonによ る血流一時遮断を行っている。

前床突起を削除する場合に蝶形骨洞や笠骨洞が開放する ことがある，その際には，粘膜を損傷しないようにして骨 蠟と Oxycelにて packing し術後の髄液鼻漏を予防する.

海綿静脈洞からの出血に対しては Oxycel のみを充填し て対処する.開放した海綿静脈洞壁の縫合は不要である.

\section{2. 手術接近法}

海綿静脈洞の立体的構造を模式的に表現すると, 中頭蓋 窩内側先端部が前床突起の下の部分に押し込まれた直方体 1)として考えられる (Fig. 1). 海綿静脈洞を前半部, 後半 部に分けると, 前者は pterional, 後者は subtemporal の アプローチが最適と思われる.

pterional approach で接近した場合 (Fig. 2), 海綿静脈 洞の上壁からアプローチすることになる，前床突起および 視神経管の上部を削除するが，これには硬膜外に削除する 方法と硬膜内にアプローチし，硬膜を切除したのち削除す

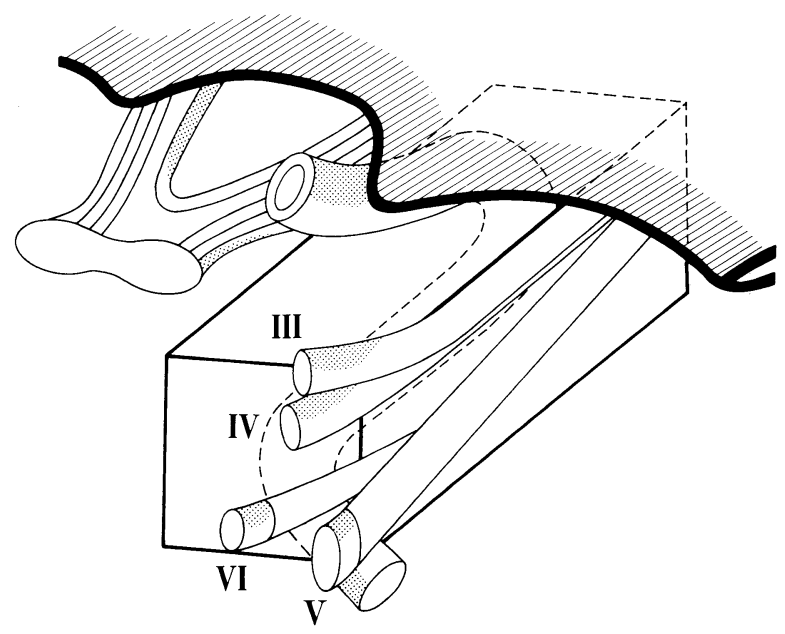

Fig. 1 This is a scheme of rt. cavernous sinus. $\mathrm{II}=$ optic nerve; III = oculomotor nerve; $\mathrm{IV}=$ trochlear nerve; $\mathrm{V}=$ trigeminal nerve; $\mathrm{VI}=$ abducens nerve.

る方法がある. 続いて内頸動脈上の硬膜を切開し, 内頸動 脈の硬膜穿通部 (Perneczky ${ }^{2)}$ の dural ring) を切開すると通 常はまず内頸動脈 $\mathrm{C}_{3}$ の一部が見え， $2 \sim 3 \mathrm{~mm}$ proxymal に進んだところで海綿静脈洞上壁が認められる。この部は。 硬膜を切開するのみで露出可能である．海綿静脈洞上壁を 切開すれば, $\mathrm{C}_{3}$ の前面, 外側, 背側の露出が可能であり, 動眼神経の内側で後方まで切開を延長すれば， $\mathrm{C}_{4}$ の背側 まで露出可能である。このアプローチは $\mathrm{C}_{2}-\mathrm{C}_{3}$ の動脈瘤が よい適応である.

次に, subtemporal approach で接近した場合 (Fig. 3), 外側壁からアプローチすることになる．動眼ないし滑車神 経, 三叉神経第 1 枝と斜台がなす三角形すなわち Parkinsonの三角からアプローチ寸れば $\mathrm{C}_{4}-\mathrm{C}_{5}$ に到達可能である.

\section{3．術中モニタリング}

内頸動脈一時遮断時のモニタリングとして, 脳血流量 $(\mathrm{CBF})$ や体性感覚誘発電位 $(\mathrm{SEP})$, 視機能のモニタリング 


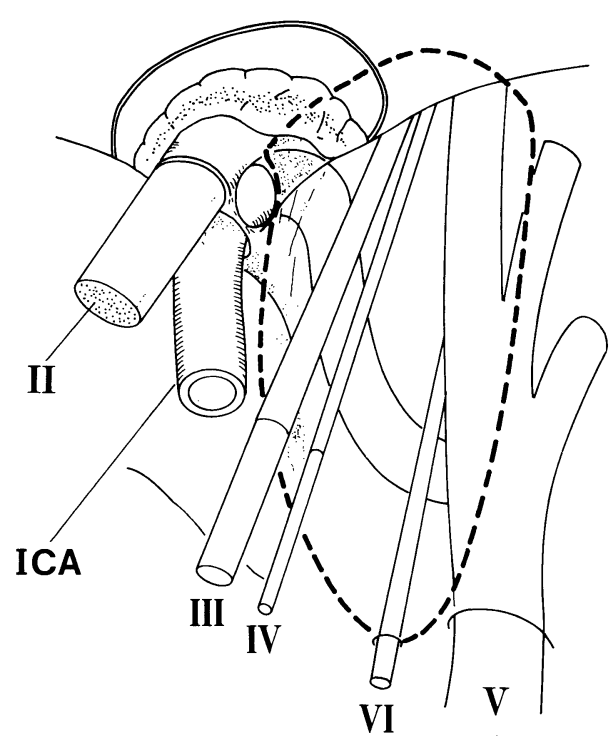

Fig. 2 This is a schematic view of rt. pterional approach. The anterior clinoid process is removed with a high-speed drill. The dural ring is exposed. Broken line indicates cavernous sinus. ICA $=$ internal carotid artery; $\mathrm{II}=$ optic nerve; $\mathrm{III}=$ oculomotor nerve; IV = trochlear nerve; $\mathrm{V}=$ trigeminal nerve; $\mathrm{VI}=$ abducens nerve.

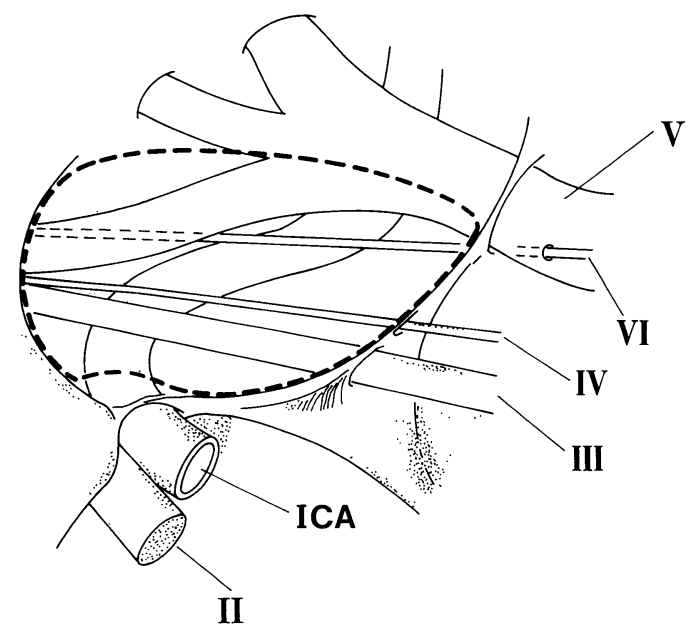

Fig. 3 This is a schematic view of rt. subtemporal approach. Broken line indicates cavernous sinus. ICA = internal carotid artery; II = optic nerve; III =oculomotor nerve; $\mathrm{IV}=$ trochlear nerve; $\mathrm{V}=$ trigeminal nerve; $\mathrm{VI}=$ abducens nerve.

として発光ダイオードによる視覚誘発電位 (VEP)などを 適宜施行している. また，静脈洞内の内頸動脈の走行や patency 確認するためにはドップラー血流計の細いプ ローブが有用である.

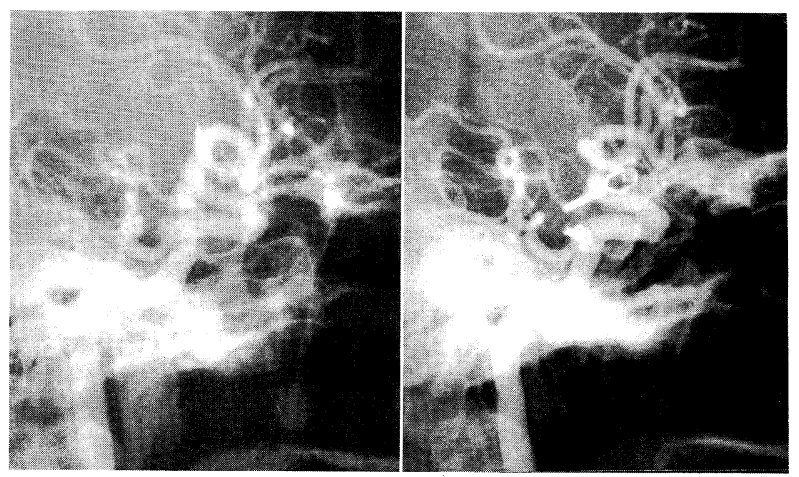

Fig. 4 Left: Right carotid angiogram demonstrates the IC-PC \& IC-PTA aneurysms. Right: Postoperative angiogram. Both aneurysms are clipped.

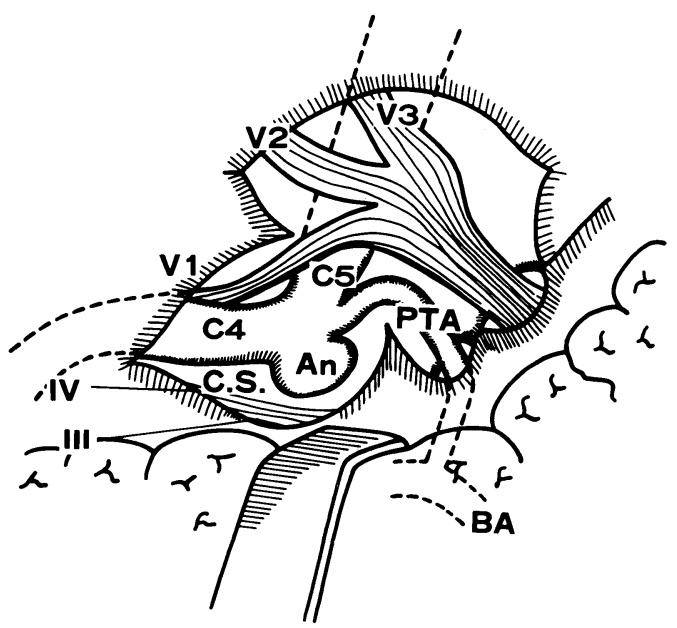

Fig. 5 Schematic drawing of the operative view in Case 1.

\section{症例}

<症例 1> 53 歳, 女性.

右眼窩周囲の突然の疼痛および右動眼神経麻痺にて発症 した。右 $\mathrm{CAG}$ (Fig. 4)にて右内頸動脈 $\mathrm{C}_{4}-\mathrm{C}_{5}$ 移行部から persistant trigeminal artery (PTA) が描出され，その起始 部に動脈瘤が認められた。また，内頸動脈後交通動脈分岐 部にも動脈瘤を認めた，右後交通動脈瘤を処置後 subtemporal にアプローチした。まず三叉神経半月神経節の膨隆 を硬膜内から確認し, 硬膜を切開すると三叉神経を認めた。 内頸動脈の走行をドップラーで確認しながら，第 1 枝に沿 って海綿静脈洞に向かった。海綿静脈洞を開放し，Oxycel を充填して出血に対処し， $\mathrm{C}_{4}, \mathrm{C}_{5}$ 部を露出した. PTA の分岐部に約 $4 \mathrm{~mm}$ の動脈瘤を認め clipping した (Fig. 5). 術後の右 CAG (Fig. 4) で動脈瘤は消失していた が ophthalmoplegia が残存しだ). 


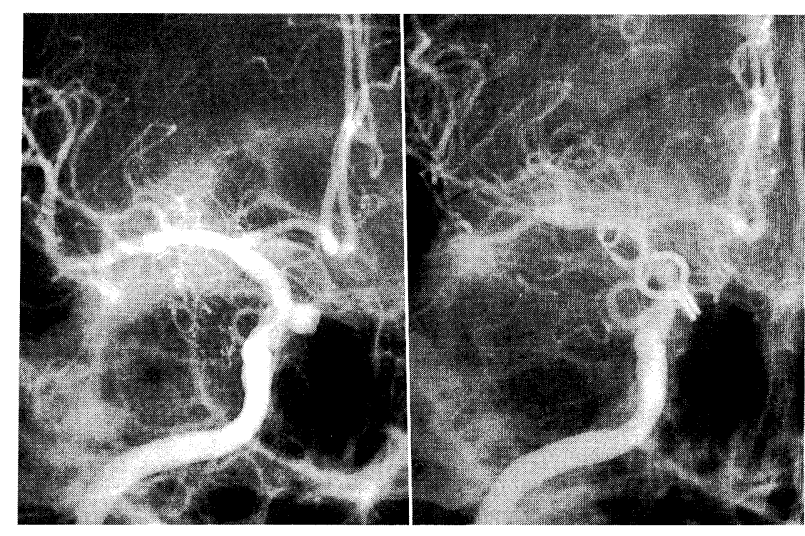

Fig. 6 Left: Right carotid angiogram, slight oblique view, demonstrates the intracavernous aneurysm. Right: Postoperative angiogram shows obliteration of the aneurysm.

<症例 2>61 歳, 男性

右 CAG (Fig. 6) にて $\mathrm{C}_{3}$ に内側向きの動脈瘤を認めた. 右 pterional approachにて前床突起を慎重に削除した。海 綿静脈洞を開放し， $\mathrm{C}_{3}$ まで露出した後，術野にクリップ を置き術中脳血管撮影を施行した，術中脳血管写を参考に して有空クリップにて clipping した. 本症例では内頸動 脈の操作中にVEP が消失し, 術後右視力を衰失した。術 後の脳血管撮影では眼動脈は patent で, 眼底動脈圧も正 常であった。

$<$ 症例 $3>66$ 歳, 女性.

左 $\mathrm{CAG}$ (Fig. 7) にて $\mathrm{C}_{2}$ に neck を有する眼動脈動脈瘤 を認めた. 左の pterional approach にて前床突起に至ると 動脈瘤により菲薄化された視神経が認められた。前床突起 を硬膜内外から削除，一部視神経管も開放した。また，副 鼻腔が開放したが，骨蠟とOxycel を充填し閉鎖した。 dural ring を切開し, neck のproxymal, distal, 眼動脈を 確認後, clipping した。術後動脈瘤は消失した。一過性の 髄液鼻瘦が認められたが, 新たな神経症状は出現しなかっ た。

\section{結果}

$\mathrm{C}_{4-5}$ のPTA の動脈瘤は subtemporal, 他の 8 例には pterional approach を用いた. 術後の脳血管撮影では全例 clipping が確認され, 内頸動脈の狭窄も認められなかった. 術後の症状は, 患側で視力を喪失したものが 2 例, ophthalmoplegia が残存したものが 1 例, 一過性に複視, 髄液 鼻漏を生じたものが抢のおの 1 例という結果であった

(Table 1).

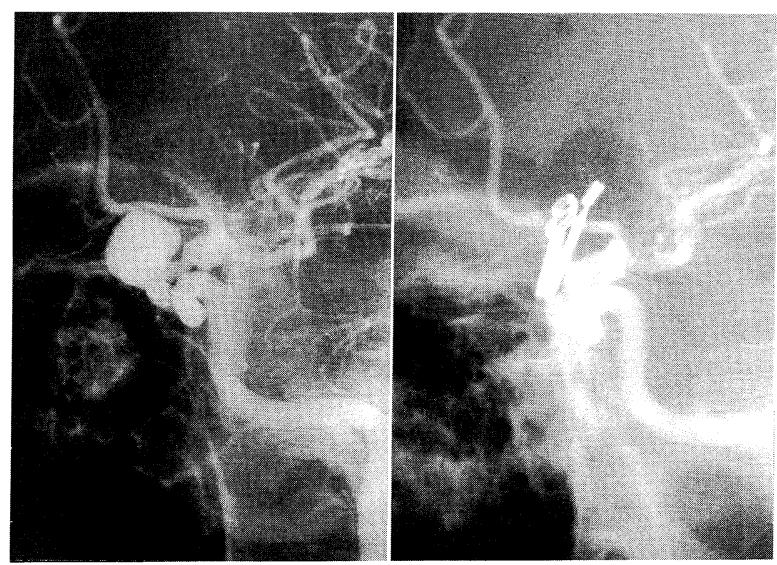

Fig. 7 Left: Left carotid angiogram demonstrates ICophthalmic aneurysm whose neck is from $\mathrm{C}_{2}-\mathrm{C}_{3}$ junction to $\mathrm{C}_{2}$ portion. Right: Postoperative angiogram.

\section{考察}

海綿静脈洞部の直達手術は 1965 年に Parkinson が頸動 脈海綿静脈洞瘻に対して低体温・心停止下に行ったのが最 初の報告 ${ }^{4)}$ である。以来，同部は手術困難な部位と考えら れてきたが，最近ではかなり多くの直達手術の報告 ${ }^{3) － 12) ~}$ が見られるようになっていきている.

我々は海綿静脈洞 “部”動脈瘤として 9 例を報告したが うち 3 例は $\mathrm{C}_{2}$ の内頸動脈・眼動脈分岐部動脈瘤であり, proximalの neck 確認するために海綿静脈洞を開放した ので今回の報告に含めた。しかし，現在ではこれらの動脈 瘤の手術では視神経管上壁を開放して前床突起を削除し, dural ring を切開するのみで海綿静脈洞を開放することな しに proxymalの neckを確認できるものと考えている.

海綿静脈洞内動脈瘤の手術のアプローチに関しては Parkinson $^{4)}$, Laws ${ }^{5)}$, Mullan ${ }^{6)}$, 白馬 ${ }^{7)}$, Dolenc ${ }^{8)} ら$ の報 告が認められるが, この部の動脈瘤の場合, 前述した $2 つ$ のアプローチが基本であり，動脈瘤の部位や大きさにより， 種々の variation を用いるべきと考えている.

つぎに手術成績についてみると, 生命予後に関してはど の報告も比較的良好 ${ }^{3)}$ 12) であるが, 問題は手術による合 併症である ${ }^{6) １ 2)}$. 我々の経験では, 一過性の複視が出現 したり ophthalmoplegia の残存した症例では Oxycel の詰 めすぎが原因と思われた. Oxycel の充填は必要最小限に とどめるべきである。また，患側の視力を衰失した症例が 2 例あったが，1 例は内頸動脈の操作時にVEP が消失し， 術後の脳血管撮影で眼動脈は温存され, 眼底血圧も正常で あったことから内頸動脈から分岐する穿通枝閉塞 ${ }^{13)}$ によ る視神経そのものの循環障害と考えられた。他の 1 例は菲 薄化した視神経に対する手術操作が原因と考えられた。視 
神経管を十分に開放 ${ }^{14)}$ するなど，視機能の温存を可能な 限り心掛けるべきであると考えられた。 さらに，一過性の 髄液鼻漏を 1 例経験したが, これは前床突起削除時に副鼻 腔が開放したためであった。副鼻腔が開放した場合は頭蓋 内との交通を厳重に遮断することが重要である．髄液鼻漏 からの髄膜炎 ${ }^{77)}$ の報告もあり注意を要する.

以上の手術成績を考慮すると，難しいのは手術適応であ る。この部の動脈瘤はクモ膜下出血をきたしたもの ${ }^{8)}$ 10) 以 外は生命予後は良好と思われるが，手術の合併症として 種々の程度の脳神経麻瘏抢よび髄液鼻漏からの髄膜炎 ${ }^{778)}$, 血管閉塞による死亡例 ${ }^{2)}$ な゙゙が報告されている。 それゆえ 手術適応は慎重に決定すべきで，Diaz $5^{11)}$ と同様，現時 点では incidental な動脈瘤の適応はないものと考えている。

機能予後を良好にする目的で $\mathrm{CBF}, \mathrm{SEP}, \mathrm{VEP}$ などの 術中モニタリングが施行されている。 CBF，SEPに関し ては遮断時間の許容範囲などをある程度予測しうる ${ }^{151}$ が, VEPに関してはいまだその評価が定まらず16)，今後の開 発が待たれる。

また近年，この部の動脈瘤に対する，血管内手術の良好 な成績 ${ }^{17)}$ も散見されつつあるが，合併症の報告もあり今 後の発展に期待したい.

\section{おわりに}

海綿静脈洞部動脈瘤 9 例の直達手術並びにその成績を報 告した。この部の手術は最近報告が増えつつあるが，単に 病巣を処置する時代ではなく，より安全確実で機能予後を よくする方法を開拓していかなければならないと考えてい る.

\section{文献}

1）坚玉南海雄，佐々木達也：特殊な動脈瘤一海綿静脈洞部動 脈瘤の治療とその問題点一。循環科学 9: 26-29, 1989
2) Perneczky A, Knosp E, Vorkapic P, et al: Direct surgical approach to infraclinoidal aneurysms. Acta Neurochir (Wien) 76: 36-44, 1985

3）肾玉南海雄, 渡辺善一郎, 佐々木達也, ほか：Persistent trigeminal artery aneurysm の一直達手術例. 脳神経外科 12: $325-329,1984$

4) Parkinson D: A surgical approach to the cavernous portion of the carotid artery. Anatomical studies and case report. J Neurosurg 23: 474-483, 1965

5) Laws ER, Onofrio BM, Pearson BW, et al: Successful management of bilateral carotid-cavernous fistulae with a transsphenoidal approach. Neurosurgery 4: 162-167, 1979

6) Mullan S: Treatment of carotid-cavernous fistulas by cavernous sinus occlusion. J Neurosurg 50: 131-144, 1979

7）白馬 明：海綿静脈洞部内頸動脈瘤の直達手術。Neurosurgeons $8: 222-229,1989$

8) Dolenc VV: Direct microsurgical repair of intracavernous vascular lesions. J Neurosurg 58: 824-831, 1983

9）児玉南海雄, 佐々木達也: 海綿静脈洞病変の直達手術. Neurosurgeons 5: 243-253, 1986

10）大西英之，下村隆英，藤田豊久，ほか：海綿静脈洞内動脈 瘤の直達手術. Neurosurgeons 8: 210-221, 1989

11) Diaz FG, Ohaegbulam S, Dujovny $M$, et al: Surgical alternatives in the treatment of cavernous sinus aneurysms. J Neurosurg 71: 846-853, 1989

12) Pendl G, Vorkapic P, Richling B, et al: Strategies in intracavernous saccular aneurysms. In The Cavernous Sinus, Springer-Verlag, Wien/New York, 1987, pp 240-251

13) Day AL: Aneurysms of the ophthalmic segment. A clinical and anatomical analysis. J Neurosurg 72: 677-691, 1990

14) Dolenc VV: A combined epi- and subdural direct approach to carotid-ophthalmic artery aneurysms. J Neurosurg 62 667-672, 1985

15）渡部洋一, 宗田 庸, 渡辺善一郎，ほか：Peltier 熱勾配式 組織血流計による術中脳血流モニタリング．第 9 回東北脳 血管障害懇話会講演集, 1987, pp 73-80

16）佐々木達也，板倉 毅，佐藤正憲，ほか：Visual Evoked Potential (VEP) の術中変化と術後視機能との相関. 第 8 回 下垂体腫瘍 Workshop 講演集, 1990, pp 119-123

17）山本勇夫，佐藤 修：Detachable balloon catheter による頸 動脈海綿静脈洞瘻の治療. Neurol Med Chir (Tokyo) 24: 678-688, 1984 